\title{
FMEA Approach for Decreasing ERP Implementation Failure using Critical Failure Factors
}

\author{
George Wanas \\ Department of Information Systems and \\ Technology \\ Institute of Statistical Studies and Research
}

\author{
Nagy Ramadan Darwish \\ Department of Information Systems and \\ Technology \\ Institute of Statistical Studies and Research
}

\begin{abstract}
The Enterprise Resource Planning (ERP) implementation projects have high failure rates. Any conflict done during the ERP implementation process leads to errors in business decision making, decrease productivity and profitability, and can affect the project success. The main purpose in this paper using Failure Modes Effects Analysis (FMEA) approach to deal with help in increasing the success rate of ERP implementation projects. This achieved through defining main failures and failure factors related to ERP implementations. The ERP projects are divided into three stages; Pre, during and post implementation. Each stage analyzed to define its main characteristics and its different failures and failure factors. Many risks can affect and lead to failure in ERP Implementation. The risk management techniques are very useful before, during and post ERP Implementation phases. The FMEA approach assesses and evaluates the defined failures and failure factors providing a quantitative measure for each risk of failure. Our study describes how to reduce ERP Failures by decreasing the risk value, so the researchers enhance the FMEA approach by a Proposed Enhanced FMEA approach to measure the risk. Based on the four organizational critical areas the researchers' uses four sub categorization aspects, Financial, Customer, Legal \& Regulation, and Business Operation. The Enhanced FMEA approach leading to success of ERP implementation.
\end{abstract}

\section{General Terms}

Failure Modes Effects Analysis, Enterprise Resource Planning.

\section{Keywords}

Information and Communications Technology (ICT), Information Technology Transfer (ITT), Critical Failure Factors (CFF), User Requirements Specifications (URS).

\section{INTRODUCTION}

ERP system is a standard software package that integrates all business activities, business information across the firm, manages the available resources, and improves its business process [1-12] [13]. ERP system Control and manage complex business process and business information effectively [3] [14], the important benefits from ERP system allow better access to information [15]. There are many reasons which motivate the organizations for implementing ERP such as replacing old system and improving operational system performance [16].

Also, the elimination of data redundancy and the simplicity of business process are important strengths of ERP system, which has highly technical cross functional through the organization. ERP systems improve organizational performance and competitiveness [17] [18] [19].

ERP has many activities that managers use to manage the organizational activities such as purchasing, human Resources, accounting, production, and sales. There are many functions available in each ERP system, such as purchasing, inventory, supply chain planning, scheduling, quality control, and demand management. Financial that contains many modules as the following Accounts Payable, Accounts Receivable, Cash Management, and control. Projects that contain many modules at the following activity management, project billing, and project contracts. Human Resources contains many modules as the following time and attendance, training, payroll, and recruiting. Customer Relationship Management that contains many modules as the following services, calls center support, sales and marketing, and analytics.

The analysis for vendors market are very important issue when the company starts thinking about implementing the ERP system. After choosing proper vendor information about the capabilities of its system should be identified [20].

There are three stages in ERP implementation, ERP pre implementation stage contains the selection of ERP software, vendors, and defines URS. ERP Implementation phase contains activities related to software configuration, data conversion, integration, testing, and user training. ERP Post implementation stage contains the user training, and maintenance, management, and evolution.

The potential Risk is losing or gaining something. Risk can defined as uncertainty [21]. Failure is a state of not meeting a desirable objective and may be viewed as the opposite of success [22] [23].

Critical Success Factor (CSF) and Critical Failure Factors approaches used to in Information System evaluation. It has been applied to in information system area including project management, manufacturing system implementation, re engineering, and ERP system implementation [13] [24].

The ERP validation assures proper control the functional risk, Operational risk and also ensures user satisfaction and ensures that the ERP meets the user's requirements and expectations. The ERP system Validation includes software validation and Infrastructure Qualification for Hardware and equipment. The business process identification known as process mapping is a critical step in validation phase for ERP, a risk analysis are very important for correct system validation and development of system documentation which includes User Requirements Specification (URS), Functional Specification (FS), Configuration Specification (CS), Installation Qualification (IQ), and Operation Qualification (OQ).

There are different risk assessment tools which try to measure the Risk, each tool has its own characteristics, features, or criteria, these tools are differentiated from IS / ERP measurement approaches and models. These models did not 
measure the risk specifically put measure IS or ERP. Risk Assessment tools used in industrial fields [25].

There are many tools can be used to perform risk assessment such as Preliminary Hazard Analysis (PHA), Functional Failure Analysis (FFA), HAZard and OPerability studies (HAZOP), Fault Tree Analysis (FTA), Hazards Analysis and Critical Control Point (HACCP), and Failure Mode and Effect Analysis (FMEA).

The study problem exists because ERP System are considered as a major investment, Around 75\% of ERP implementation projects fail in achievement their goals, ERP System require efficient planning, and If ERP Apps fail to achieve Organizational goals [12] [13] [15] [26], for that, the management of ERP risk are very important for leading to ERP system success to ensure that ERP system success in achieving the business requirements. A different ERP system has different degrees in spending time on the implementation. The much of adjusting may be a step towards failure [24].

Many researchers have found that the weak of risk assessment the main reason that leads to the ERP implementation failure [27-29]. The organization must validate the ERP to assure that the ERP system meet the organizational requirements.

The paper consists 7 parts, part 1 is the Introduction, part 2 contains the Literature review, part 3 contains Main Failure Factors Assessment, part 4 includes the FMEA Approach, part 5 contains a paper conclusion and finally last part including the references.

\section{LITERATURE REVIEW}

There are many researchers interested in the areas of Risk and Failure, Risk control, Risk assessment, and Risk management as a general point of view. Also, there are many researchers interested in the areas of ERP risk and failure. The most important topic that received high focus from researchers was Risk evaluation and measurement, Critical Success Factors and Critical Failure Factors for ERP Implementations, Risk ranking and prioritization, Risk priority number (RPN), and Risk assessment and management Tools.

\subsection{ERP Risks and Failure:}

The ERP Implementations are risky projects. The Risk assessment is a very important solution for ERP Improvement and success that contains risk identification, analysis, and prioritization. Risk is categorized as functional risk and configuration risk.

The analysis for software failures is a difficult task since it is related to complex systematic business process with many variables compared to hardware failures which has limited variable. In addition to Identifying the strength and weakness of organizations can help in reducing the effect of failure.

\subsection{ERP implementation difficulties:}

The ERP implementation constraints that facing developing countries compared with developed countries.

\subsubsection{The National Factors:}

Are the great challenge for ERP Implementation, It includes Information \& Communications Technology (ICT) infrastructure, an economical status of the country, manufacturing industrial strength, regional location, and governmental regulations [16] [30-31].

\subsubsection{Organizational Factors:}

Such as Computer culture, IT Maturity, Management Commitment, Business Size, ERP cost, and BPR experience.
[13] [16] [32] [30] [33], all business units at different countries had different way of how business done because of different business process and local requirements [30]. Many of ERP failures in Egypt are caused by customization of ERP system to match the existing processes instead of restructuring them [13] [31].

\subsubsection{Information Technology Transfer problems:}

$($ ITT)

Cultural issues facing the eastern developing countries when implementing and using western technologies, management procedures, and information systems and techniques. [13] [16] [32] [30] [33]

\subsubsection{Business justifications}

Most of the implementation failures in ERP were early ERP adoptions which did not have strong business justifications. [32].

\subsection{Risk assessment tools:}

There are many tools that are able to assess risk in general, such as Preliminary Hazard Analysis (PHA), Hazard \& Operability Study (HAZOP), Fault Tree Analysis (FTA), Hazards Analysis \& Critical Control Point (HACCP), and Failure Mode \& Effect Analysis (FMEA), the PHA, FTA, and HAZOP tools are used in early stages in the requirement analysis and at the design process. They support qualitative not quantitative analysis [34] [35] that is why these tools are not preferred for ERP Implementation, the FTA does not consider the severity of failure [36] and in complex system such as ERP that includes large number of equipment and process variables the fault tree becomes lager and takes long time to be completed, and they become much more difficult to solve [34] [37-38], and also these make FTA not a preferred choice, and takes a long time to be completed, and they become much more difficult to solve [34] [37-38], and also these make FTA, not a preferred choice, HACCP is originated in the food industry [39][40], and hence it is more logic to used it in ERP system Implemented in food industry.

FMEA methodology gives a clear description of the failure modes [41], FMEA methodology is now used in a variety of industries such as Software [22] [40] [42-45], FMEA purpose is to examine possible failure modes and determine the impact of these failures on many stages by Design FMEA (DFMEA), Process FMEA (PFMEA), Machinery or Equipment FMEA (MFMEA) or Service FMEA (SFMEA) [22][41], FMEA is a strategic technique for creation of error free services operation [46]. And it is a methodology that focuses on prioritizing critical failures to safety improvement [47]. FMEA considers each mode of failure for every component of a system, [45].

Table 1. Risk assessment tools

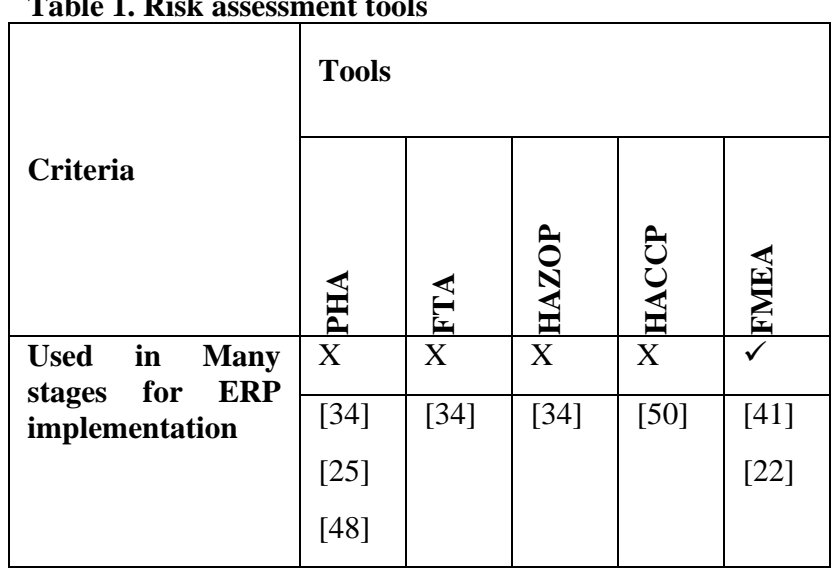




\begin{tabular}{|c|c|c|c|c|c|}
\hline & [49] & & & & \\
\hline \multirow{5}{*}{$\begin{array}{l}\text { Quantitative } \\
\text { Tools }\end{array}$} & $\mathrm{X}$ & $\mathrm{X}$ & $X$ & $\checkmark$ & $\checkmark$ \\
\hline & [34] & [34] & [34] & [54] & [55] \\
\hline & [25] & [51] & [52] & & \\
\hline & [49] & & [21] & & \\
\hline & & & [53] & & \\
\hline \multirow{3}{*}{$\begin{array}{l}\text { Consider Severity } \\
\text { of the failures }\end{array}$} & $\checkmark$ & $\mathrm{X}$ & $\checkmark$ & $\checkmark$ & $\checkmark$ \\
\hline & {$[52]$} & [36] & [53] & [50] & [55] \\
\hline & & & & [54] & \\
\hline \multirow{3}{*}{$\begin{array}{l}\text { Prioritizing } \\
\text { critical failures }\end{array}$} & $\checkmark$ & $\mathrm{X}$ & $\checkmark$ & $\checkmark$ & $\checkmark$ \\
\hline & {$[25]$} & [51] & [53] & [56] & [47] \\
\hline & & & & & [25] \\
\hline \multirow{4}{*}{$\begin{array}{lr}\text { Give } & \text { clear } \\
\text { description } & \text { of } \\
\text { failure } & \text { mode } \\
\text { (Reason } & \text { of } \\
\text { Hazard) } & \end{array}$} & $\checkmark$ & $\checkmark$ & $\checkmark$ & $\checkmark$ & $\checkmark$ \\
\hline & {$[51]$} & [25] & [51] & [54] & [41] \\
\hline & & [51] & & [56] & [55] \\
\hline & & & & & [57] \\
\hline \multirow{4}{*}{$\begin{array}{lr}\text { Powerful } & \text { in } \\
\text { complex } & \text { system } \\
\text { such as ERP }\end{array}$} & $\checkmark$ & $\mathrm{X}$ & $\checkmark$ & $\mathrm{X}$ & $\checkmark$ \\
\hline & {$[52]$} & [34] & [52] & {$[50]$} & [55] \\
\hline & & [38] & & & \\
\hline & & [51] & & & \\
\hline \multirow{6}{*}{$\begin{array}{l}\text { Used in variety of } \\
\text { industry over the } \\
\text { world including } \\
\text { Software }\end{array}$} & $\checkmark$ & $\checkmark$ & $X$ & $\mathrm{X}$ & $\checkmark$ \\
\hline & {$[48]$} & [58] & [59] & [39] & [42] \\
\hline & & & & [25] & [43] \\
\hline & & & & [50] & [22] \\
\hline & & & & [54] & [57] \\
\hline & & & & & [60] \\
\hline \multirow[t]{3}{*}{ Product error free } & $\checkmark$ & $\checkmark$ & $\checkmark$ & $\checkmark$ & $\checkmark$ \\
\hline & [25] & [25] & [25] & {$[50]$} & [22] \\
\hline & & & & [54] & \\
\hline \multirow{2}{*}{$\begin{array}{l}\text { Services operation } \\
\text { error free }\end{array}$} & $\checkmark$ & $\checkmark$ & $\checkmark$ & $\mathrm{X}$ & $\checkmark$ \\
\hline & {$[25]$} & {$[51]$} & [53] & {$[50]$} & [46] \\
\hline
\end{tabular}

According to table 1, the researchers conclude that FMEA is powerful Quantitative risk assessment tool for ERP Risk Assessment.
The researcher uses FMEA to assess the risk factors related to different implementation stages.

\section{FAILURE FACTORS ASSESSMENT}

CFF used to decrease the ERP implementation failure. Many researchers study CFFs that widely used in the information system area, it's lead to the ERP implementation success [4] [12-13], the following are the most common failure factors,

Organization Fit that described as the compatibility between ERP requirement and organizational characteristics, ERP Teamwork and Skill Mix factor contain Technical and business experts Cooperation as well as end users, lack of Project Management lead to Poor ERP implementation project management may cause failure in ERP Apps, Software System Design should be established before ERP deployment, ERP architecture should be established before implementation, Lack of user involvement and Training contain User commitment and a project champion in the early stages of the project lead to ERP implementation failure, Key users should be have system utilities satisfaction, Technology Planning configuring an appropriate infrastructure that Can lead to ERP implementation success, Communication expectations or goals at every level needed for success ERP implementation, Legacy System and Information Technology factor lead to Implementation success for that ERP system require people for working within the system and not around it, lack of Change Management lead to ERP implementation, Change Management contain Enterprise structure and culture change should be managed which includes people, organization, and culture change, Business Process Reengineer (BPR) is a very important factor In the process of ERP configuring, reengineering should occur frequently to gain the advantage of the system, Top Management Support needs to identify the project as a top priority, Lake of financial Support and costs analysis might impact the ERP adoption, cause the failure of system implementation projects [5] [6] [12] [42].

\section{FMEA APPROACH}

The FMEA approach is evaluated potential failure and their effects. The FMEA approach can reduce or control the potential failures [61-62]. FMEA is a useful tool for reducing the failure and factors causes [62-64].

The following are the advantages of using FMEA, failure Prevention planning, Cost reduction, Decreased waste, Decreased warranty costs, Reduced non value added operations, higher product reliability, less design modification, better quality planning, continuous improvement in process design and product, Accepts a high degree of complexity, and Results can be correlated directly with actual risks [41-42].

There are many Success factors for the FMEA approach as the following, Correct risk identification and classification, Correct control factors to adequately manage risk, Correct prioritization and allocation of resources based upon RPN, Process Knowledge, Information system reliability, Data accuracy, Data integrity [42].

\subsection{Classical FMEA Approach:}

FMEA is a technique which identifies potential system (process or product) weaknesses. The FMEA approach is accepted by many companies in variety of industries around the world for identifying, prioritizing, and addressing the main potential failure effects, causes of potential failure and control factors which influence the ERP implementation success. 


\subsubsection{Risk Management rating criteria using FMEA:}

The FMEA approach contain three criteria for assessing the failure, the severity of the failure effect, how frequently the risk is likely to occur, and how easily the risk can be detected. Participants must set and agree on a degree between 1 and 5 for the severity, occurrence and detection level for each of the failure.

The Criteria for Severity, Occurrence, and Detection are defined depending on the types of problems in each ERP implementation stage (Pre, during, and post).

Severity "SEV": The severity is seriousness or impact of failure [41] [60]. The Severity criteria described as shown in Table 2.

Table 2. Severity

\begin{tabular}{|c|c|c|}
\hline $\begin{array}{l}\text { Severity } \\
\text { (Effect) }\end{array}$ & Rating & Criteria \\
\hline Insignificant & 1 & $\begin{array}{l}\text { No effect on data security, integrity } \\
\text { and/or accuracy Data can be } \\
\text { retrieved and or stored in a normal } \\
\text { operating environment, No } \\
\text { hardware damage. }\end{array}$ \\
\hline Minor & 2 & $\begin{array}{l}\text { System Downtime of up to } 15 \\
\text { minutes, but without affecting data } \\
\text { security, integrity and/or accuracy. } \\
\text { No hardware damage. }\end{array}$ \\
\hline Moderate & 3 & $\begin{array}{l}\text { Downtime of greater than } 15 \\
\text { minutes and less than } 1 \text { hours } \\
\text { and/or loss of data which has been } \\
\text { previously backup. } \\
\text { No hardware damage. } \\
\text { No effect on product safety and/or } \\
\text { quality. }\end{array}$ \\
\hline Major & 4 & $\begin{array}{l}\text { Downtime of greater than } 1 \text { hours } \\
\text { and/or loss of data security, } \\
\text { integrity and/or accuracy. } \\
\text { Hardware damage that can be fixed } \\
\text { or corrected with moderate } \\
\text { maintenance. } \\
\text { No effect on product safety and/or } \\
\text { quality. }\end{array}$ \\
\hline $\begin{array}{l}\text { Catastrophic } \\
\text { (very High) }\end{array}$ & 5 & $\begin{array}{l}\text { Downtime of greater than } 1 \text { day } \\
\text { and/or loss of data security, } \\
\text { integrity and/or accuracy. } \\
\text { Hardware damage that cannot be } \\
\text { fixed and require replacement. } \\
\text { Possible effect on product safety } \\
\text { and/or quality. }\end{array}$ \\
\hline
\end{tabular}

Occurrence "OCC": Occurrence is a likelihood assessment that causes will happen and result in a failure [41]. The Occurrence criteria described as shown in Table 3 . Occurrence describes how frequent is the cause likely to occur the risk?

Table 3. Occurrence

\begin{tabular}{|l|l|l|}
\hline Occurrence & Rank & Criteria \\
\hline Remote & 1 & $\begin{array}{l}\text { Failure occurs every year or more } \\
\left(\begin{array}{l}1 \text { failure per 8760 hours of } \\
\text { operation) }\end{array}\right.\end{array}$ \\
\hline Rare & 2 & $\begin{array}{l}\text { Failure occurs every 3 } \\
\text { months(quarter) } \\
\text { ( } 1 \text { failure per 2160 hours of } \\
\text { operation) }\end{array}$ \\
\hline Occasionally & 3 & $\begin{array}{l}\text { Failure occurs every week } \\
\text { ( } 1 \text { failure per 168 hours of } \\
\text { operation) }\end{array}$ \\
\hline Frequently & 4 & $\begin{array}{l}\text { Failure occurs every day } \\
\text { ( } 1 \text { failure per 24 hours of } \\
\text { operation) }\end{array}$ \\
\hline & 5 & $\begin{array}{l}\text { Failure occurs every shift } \\
\text { ( } 1 \text { failure per } 8 \text { hours of } \\
\text { operation) }\end{array}$ \\
\hline
\end{tabular}

Detection "DET": It is a likelihood assessment that the current controls will detect the cause of the failure [41]. The Detection criteria described as shown in Table 4. Detection describes how probable is a detection of failure cause?

Table 4. Detection

\begin{tabular}{|l|l|l|}
\hline Detection & Rank & Criteria \\
\hline Certain & 1 & $\begin{array}{l}\text { Controls certainly detect any potential } \\
\text { cause, and subsequent failure. } \\
\text { Controls will prevent a potential failure } \\
\text { and isolate the cause. }\end{array}$ \\
\hline High & 2 & $\begin{array}{l}\text { High chance that controls will detect a } \\
\text { potential cause, and subsequent failure. } \\
\text { Controls will prevent a potential failure } \\
\text { and isolate the cause. }\end{array}$ \\
\hline $\begin{array}{l}\text { Medium } \\
\text { likelihood }\end{array}$ & 3 & $\begin{array}{l}\text { Medium chance that controls will detect } \\
\text { a potential cause, and subsequent } \\
\text { failure. Controls will provide on an } \\
\text { indication of potential failure and may, } \\
\text { or may not, prevents failure. }\end{array}$ \\
\hline $\begin{array}{l}\text { Low } \\
\text { likelihood }\end{array}$ & 4 & $\begin{array}{l}\text { Controls do not prevent failure from } \\
\text { occurring. } \\
\text { Controls will isolate the cause and } \\
\text { failure mode after the failure has } \\
\text { occurred. }\end{array}$ \\
\hline $\begin{array}{l}\text { Remote } \\
\text { likelihood }\end{array}$ & 5 & $\begin{array}{l}\text { Very remote chance that controls will } \\
\text { detect a potential cause, and subsequent } \\
\text { failure mode, or there are no controls. }\end{array}$ \\
\hline
\end{tabular}




\subsubsection{Risk management Ranking criteria:}

The development of risk ranking tables assists the decision making process. Risk ranking criteria use a $5 * 5$ risk matrix as shown in [table 5] [65], the maximum score of 25 is obtained by multiplying the score of Severity times the Occurrence, and the least score is 1 . Risk increases from the lower left hand corner to the upper right hand corner. Each color represents zones for equal amounts of Risk. The upper right hand red zone demands special attention, this hot red zone very carefully, Address these representation with the Pareto principle. The lower left hand zone contains the most issues that have lower risks. The second area gets second level attention, followed by the yellow area. Risk management ranking criteria calculated depending on Severity and Occurrence of risk.

\section{Table 5. Ranking Criteria}

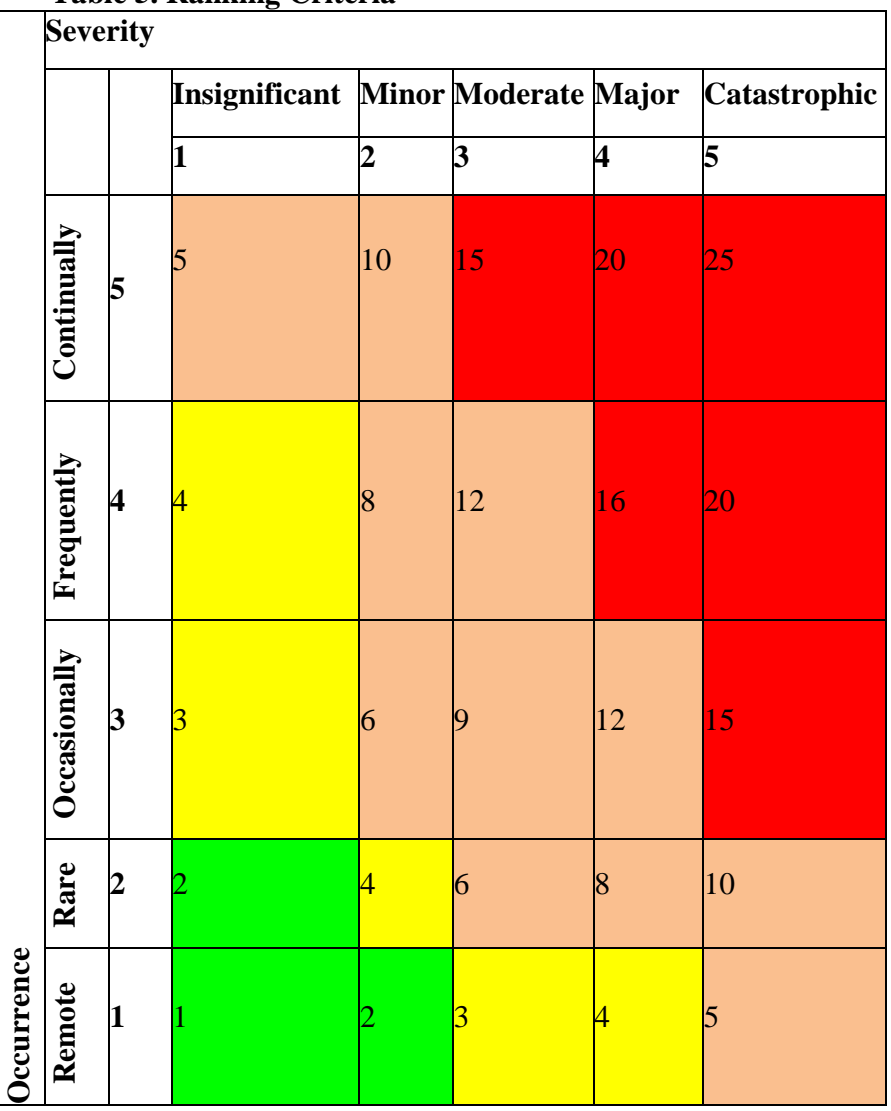

\subsubsection{Risk Evaluation:}

Each Failure is scored using a predefined table based on a subject matter expert (SME) team's assessment of the element's contribution. The analysis begins with the SME team defining a scoring table for the three elements. Using the table, the SME team scores the three elements of each failure. A risk priority number (RPN) is calculated for each failure as the product of scores for each element Severity, Occurrence, and Detection as in Table 6.

RPN = Risk priority number, in order to rank concerns, Calculated as SEV x OCC $x$ DET
Table 6. Risk Range

\begin{tabular}{|l|l|}
\hline Risk Range & Criteria \\
\hline 001: 010 & Insignificant \\
\hline 011: 050 & Minor \\
\hline 051: 080 & Moderate \\
\hline 081: 100 & Major \\
\hline 100: 125 & $\begin{array}{l}\text { Catastrophic } \\
\text { (Very High) }\end{array}$ \\
\hline
\end{tabular}

\subsection{FMEA application Model for ERP Implementation:}

To prioritize the CFF in ERP implementation using FMEA model, CFFs are considered as the potential failure causes in FMEA approach [42], there are five steps as the following,

Step1 Potential Failure Specification is the inability of ERP system implementation, Step2 Potential Failure Effects Specification is the result of a system failure mode is a potential effect of the Step3 Potential Failure Causes Specification that are the system design deficiencies that result in the failure mode in ERP implementation, Step4 Failure Modes Control includes the method that can be used for identifying and preventing the failure occurs in ERP implementation process, Step5 Risk Prioritizing of failure modes by using risk priority number (RPN) [60].

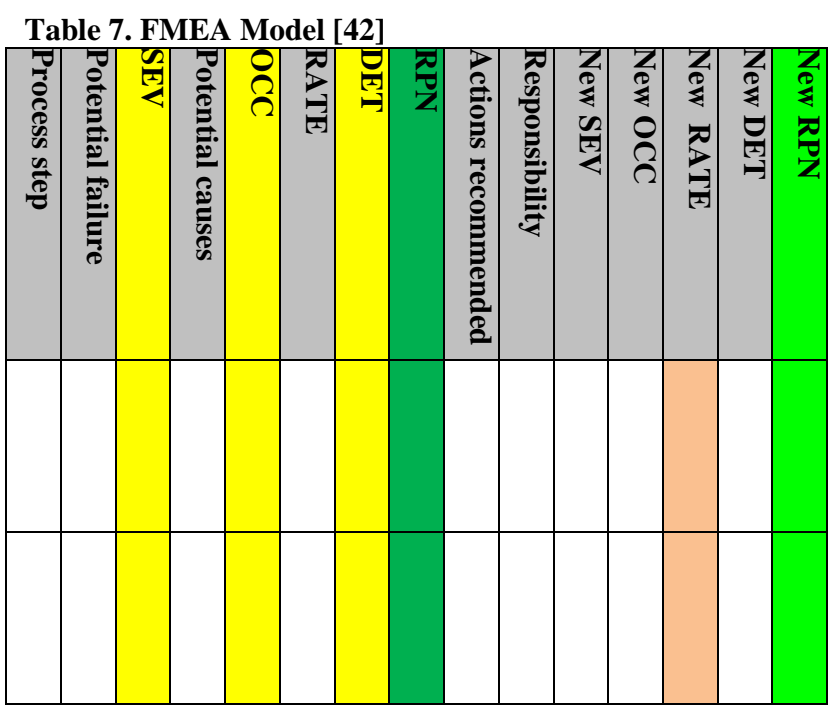

\subsection{Enhanced FMEA Approach:}

Enhanced FMEA Approach [Figure 1] provides for Identifying, prioritizing, and addressing the main potential failure effect, potential failure causes and control factors which influence the successful implementation of ERP. A enhanced FMEA approach measure the risk based on four sub categorization aspects, Financial, Customer, Legal \& Regulation, and Business Operation.

\subsubsection{Risk evaluation rating criteria:}

Using Enhanced FMEA Approach to calculate three Values Max Severity, Max Occurrence, and Max Detection. 
Participants must set and agree on a degree between 1 and 5 for the severity, occurrence and detection level for each sub categorization aspects of the failure.

There are an extension in calculation method for the severity, occurrence, and detection criteria based on four sub categorization aspects, Financial, Customer, Legal \& Regulation, and Business Operation. The calculation for severity or occurrence or detection for the risk will determine based on the four sub categorization aspects that illustrate the following table [Table 8].

Table 8. Ranking Criteria

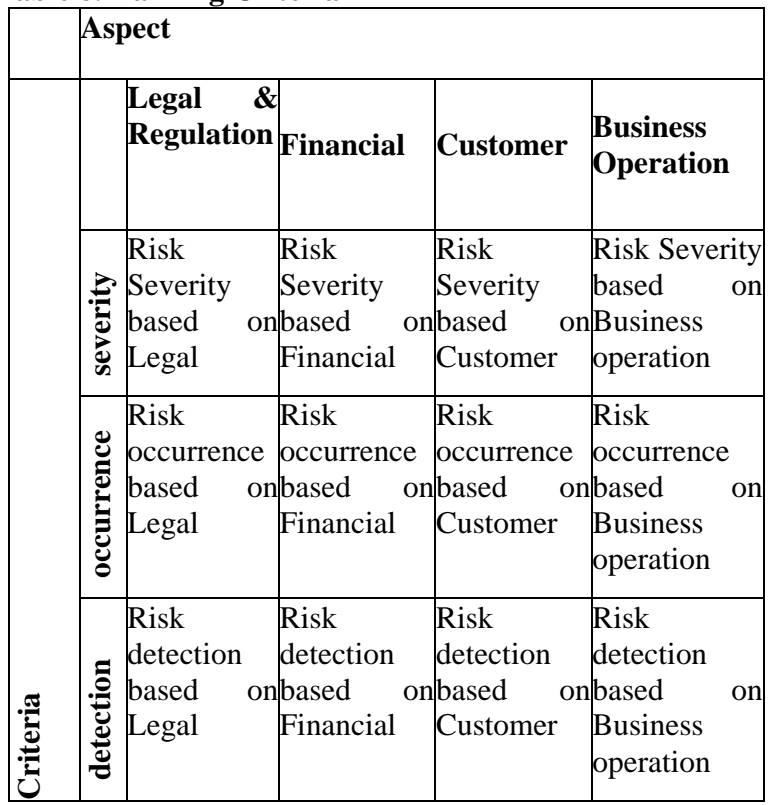

\section{Max Severity "MSEV":}

Severity criteria are shown in [Table 2]. Determine the maximum severity by comparisons between the four aspects for Severity criteria, "Risk Severity based on Legal, Risk Severity based on Financial, Risk Severity based on Customer, and Risk Severity based on Business operation".

MSEV = Max (Risk Severity based on Legal, Risk Severity based on Financial, Risk Severity based on Customer, Risk Severity based on Business operation)

\section{Max Occurrence "MOCC":}

Occurrence criteria are shown in [Table 3]. Determine the maximum occurrence by comparisons between the four aspects for occurrence criteria, "Risk occurrence based on Legal, Risk occurrence based on Financial, Risk occurrence based on Customer, and Risk occurrence based on Business operation".

MOCC $=$ Max (Risk occurrence based on Legal, Risk occurrence based on Financial, Risk occurrence based on Customer, Risk occurrence based on Business operation)

\section{Max Detection "MDET":}

Detection criteria are shown in [Table 6]. Determine the maximum detection by comparisons between the four aspects for detection criteria, "Risk detection based on Legal, Risk detection based on Financial, Risk detection based on Customer, and Risk detection based on Business operation".

MDET $=$ Max (Risk detection based on Legal, Risk detection based on Financial, Risk detection based on Customer, Risk detection based on Business operation)

\subsubsection{Risk Evaluation Max Ranking criteria:}

The development of risk max ranking tables assists the decision making process. Risk max ranking criteria use a $5 * 5$ risk matrix as shown in [Table 9], the maximum score of 25 is obtained by multiplying the score of Greater Severity times the Greater Occurrence, and the least score is 1. Risk increases from the lower left hand area to the upper right hand area. Each color represents zones of equal amounts of risk. The upper right hand red zone demands special consideration and special attention, this hot red zone very carefully, address these issues with the Pareto principle. The lower left hand area contains the most issues that have lower risks. The second area gets second level attention, followed by the yellow area. Risk management ranking criteria calculated depending on Max Severity and Max Occurrence of risk.

Table 9. Max Ranking Criteria

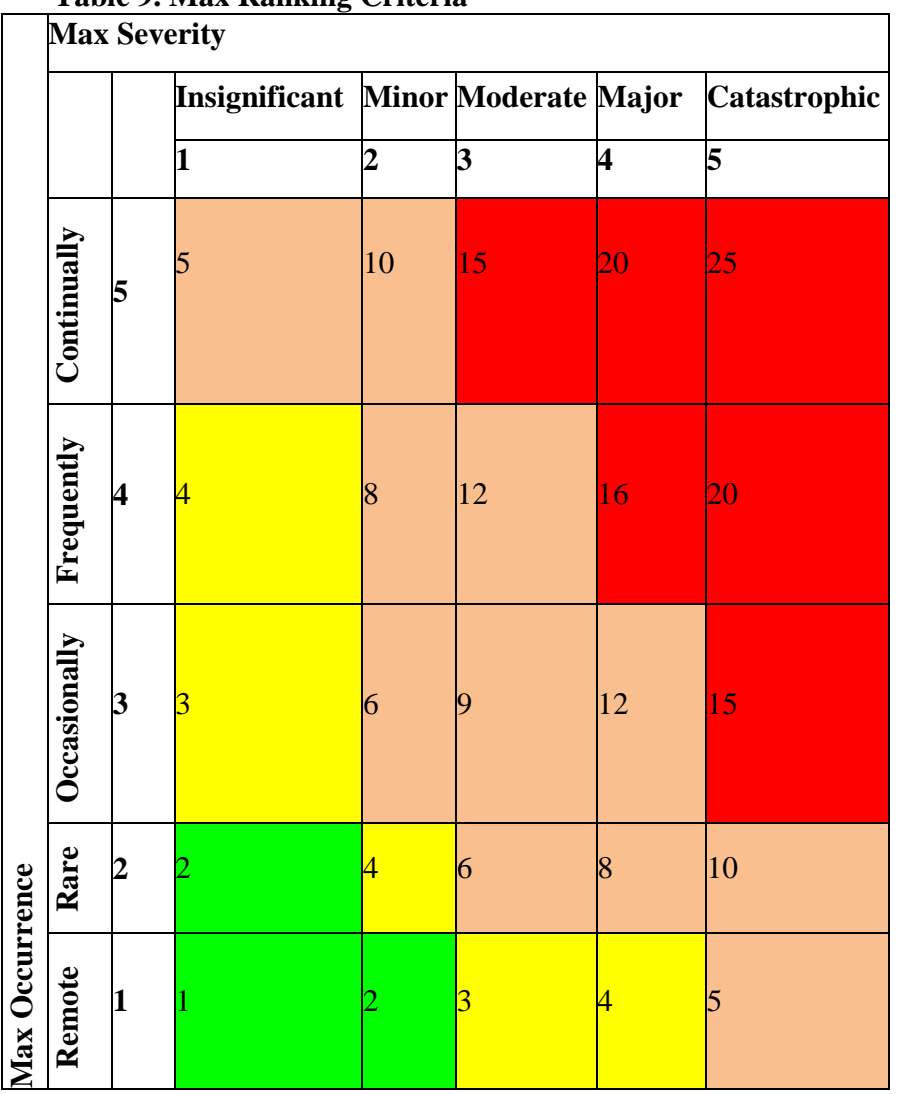

\subsubsection{Risk Evaluation:}

Each Failure is scored using a predefined table based on a subject matter expert (SME) team's assessment of the element's contribution. The analysis begins with the SME team defining a scoring table for the three elements. Using the table, the SME team scores the three elements of each failure. Based on four sub categorization aspects Financial (F), Customer (C), Legal \& Regulation (L), Business Operation (B), a Max risk priority number (MRPN) is calculated for each failure as the product of scores for each element Max Severity, Max Occurrence and Max Detection as in [Table 10] [Figure 1].

MRPN = Max Risk priority number in order to rank concerns, Calculated as MSEV x MOCC x MDET.

Example describes the four sub categorization aspect on the risk, if a firm use illegal applications, based on Legal \& Regulation aspects a firm will receive complains from the Application owner, and based on Financial aspects a firm will 
pay a lot of money for the complains penalty, and based on Business Operation aspect may be the system crash and no have operation maintenance, and based on Customer aspect the illegal applications billing system may be unstable which exposes us to lose our customers.



Fig 1: Enhanced FMEA Approach 
Table 10. Enhanced FMEA Approach

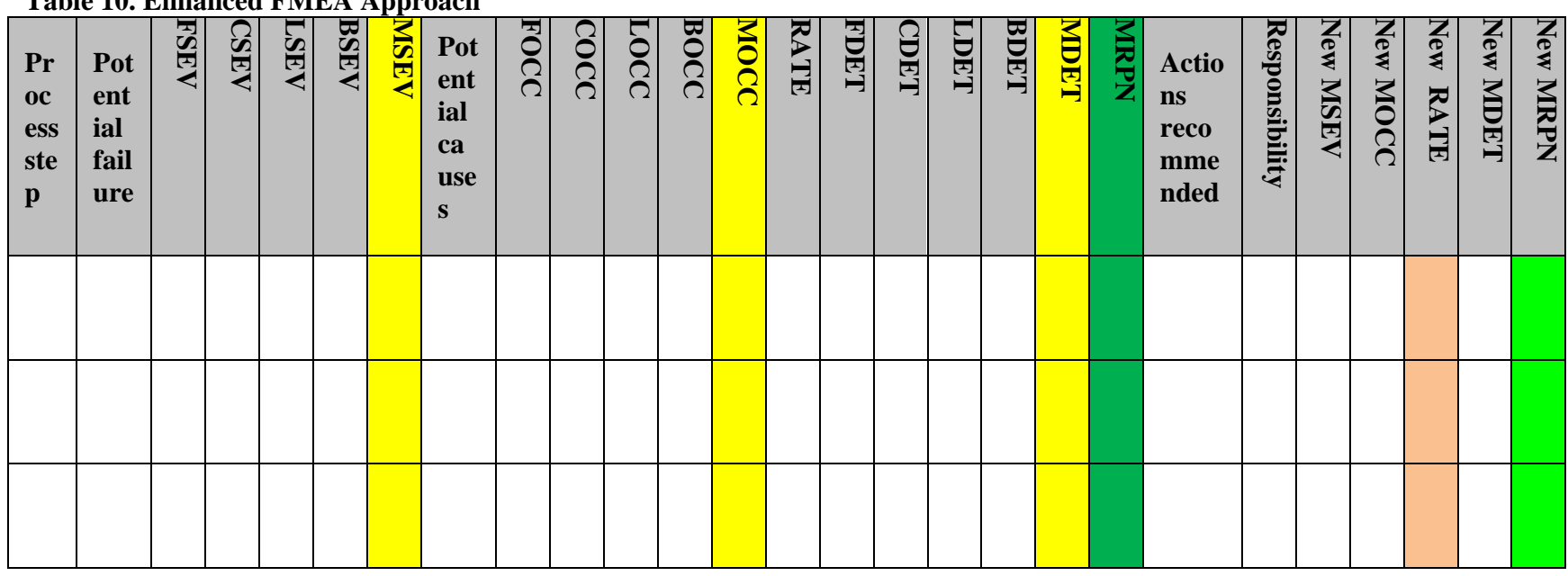

FSEV refers to Risk Severity based on the financial aspect.

CSEV refers to Risk Severity based on Customer aspect.

LSEV refers to Risk Severity based on Legal \& Regulation aspect.

BSEV refers to Risk Severity based on Business operation aspect.

MSEV refers to Max Severity

FOCC refers to Risk Occurrence based on the financial aspect.

COCC refers to Risk Occurrence based on Customer aspect.

LOCC refers to Risk Occurrence based on Legal \& Regulation aspect.

BOCC refers to Risk Occurrence based on Business operation aspect.

MOCC refers to Max Occurrence

FDET refers to Risk Detection based on the financial aspect.

CDET refers to Risk Detection based on Customer aspect.

LDET refers to Risk Detection based on Legal \& Regulation aspect.

BDET refers to Risk Detection based on Business operation aspect.

MDET refers to Max Detection

MRPN refers to Max Risk priority number

New MSEV refers to New Max Severity

New MOCC refers to New Max Occurrence

New MDET refers to New Max Detection

New MRPN refers to NEW Max Risk priority number

\section{CONCLUSION AND FUTURE WORK}

It is concluded that ERP system are complex and cross functional systems control all organization activities. Successful ERP implementation projects are considered as one of the core competencies for any organization. Implementation of ERP systems includes multiple risks that need to be addressed and controlled on scientific bases. ERP systems have a high failure rate that needs to be known and decreases in every ERP implementation phases, pre implementation, during implementation and post implementation. Using a CFF approach useful to define main failures and failure factors related to ERP implementations, It's very useful to apply the Enhanced FMEA Approach in the three phases of ERP implementation, before, during and post ERP Implementation, there are three important criteria in FMEA, Severity, Occurrence, and Detection. The Enhanced FMEA Approach useful for helping in increasing the success rate of ERP implementation projects, the researchers contribute that design the Enhanced FMEA Approach based on four sub categorization aspects, Financial, Customer, Legal $\&$ Regulation, and Business Operation.

For future work in this area, Risk factors are highly dependent and the acceptance of risk values depends on the industry type. Therefore, Risk Acceptance level may need more enhancements to be automatically justified without human interference. The researchers will applying the proposed approach in many ERP projects.

\section{REFERENCES}

[1] Rajendra Marulkar, Vijay Kumar Dharmadhikari and B. V. Cadambi "ERP Software Development For Pressure Die-casting Industry”, Mar 2012

[2] Chetan S. Sankar "factors that improve ERP implementation strategies in an organization”, June 2010

[3] Hany Elbardan "Enterprise Resource Planning (ERP) Systems Implementation and Internal Audit Function (IAF) Change: Case Study Approach”, 28 Mar 2012

[4] Azadeh Pishdad, Abrar Haider,and Andy Koronios "ERP ASSIMILATION: A TECHNOLOGY INSTITUTIONALISATION PERSPECTIVE” ,June 2012

[5] Mutaz M. Al-Debei and Enas M. Al-Lozi "Implementations of ICT Innovations: A Comparative Analysis in terms of Challenges between Developed and Developing Countries" ,2012

[6] Mustafa Abdullabhai and Freddie Acosta "Impact of Adopting Enterprise Resource Planning Systems by Commercial Organizations in Kenya”, Feb 2012

[7] Belal Saleh Mareai and S. Y. Patil "TAXONOMY OF ENTERPRISE RESOURCE PLANNING SYSTEM" ,June 2012 
[8] L Kambarami, $\mathrm{S}$ Mhlanga and $\mathrm{T}$ Chikowore "EVALUATION OF ENTERPRISE RESOURCE PLANNING IMPLEMENTATION SUCCESS: CASE STUDY IN ZIMBABWE”, July 2012

[9] Syed Iftikhar H. Shah, Abdul Zahid Khan, Rahat. H. Bokhari and Muhammad Abbas Raza "Exploring the Impediments of Successful ERP Implementation” ,Dec 2011

[10] ALA'A HAWARI and RICHARD HEEKS "Explaining ERP Failure in Developing Countries: A Jordanian Case Study", 2010

[11] Abeer I. ALdayel, Mashael S. Aldayel and Abdullah S. Al-Mudimigh "The Critical Success Factors of ERP implementation in Higher Education in Saudi Arabia" ,Oct 2011.

[12] Syed Iftikhar H. Shah, Rahat H. Bokhari, Shabbir Hassan, Mahmood H. Shah and Madad Ali Shah "SocioTechnical Factors Affecting ERP Implementation Success in Pakistan”,2011

[13] M. H. Rasmy, Assem Tharwat and Sondoss Ashraf "Enterprise Resource Planning (ERP) Implementation in the Egyptian Organizational Context", 2005

[14] T.SUGANTHALAKSHMI and C MOTHUVELAYUTHAN "GROUPING OF CRITICAL SUCCESS FACTORS FOR ERP IMPLEMENTATIONS”,April 2012

[15] Hany Abdelghaffar "SUCCESS FACTORS FOR ERP IMPLEMENTATION IN LARGE ORGANIZATIONS: THE CASE OF EGYPT", 2012

[16] Hany Abdelghaffar and Reem Hamdy Abdel Azim "SIGNIFICANT FACTORS INFLUENCING ERP IMPLEMENTATION IN LARGE ORGANIZATIONS: EVIDENCE FROM EGYPT”, April 2010

[17] Ayyub Ansarinejad, Mohsen-Sadegh Amalnick, Mohammad Ghadamyari, Samad Ansarinejad and Loghman Hatami-Shirkouhi "EVALUATING THE CRITICAL SUCCESS FACTORS IN ERP IMPLEMENTATION USING FUZZY AHP APPROACH”, 2011

[18] Arun Madapusi "An Overview of ERP in Indian Production Firms", Mar 2011

[19] Andreas Gidlund, Niklas Ribbenhed "Master's thesis Tailoring of ERP systems” June 2006.

[20] Valeriya Titova "Implementation of Enterprise Resource Planning service: 1C Logistics system in the warehouse processes in construction companies" March 2016.

[21] Wei WANG, and Tingdi ZHAO "The Application of the Root Causes of Human Error Analysis Method Based on HAZOP Analysis in Using Process of Weapon” 2009.

[22] Murat OZKOK "RISK ASSESSMENT IN SHIP HULL STRUCTURE PRODUCTION USING FMEA", Feb 2013

[23] Nagy Ramadan Darwish and Nancy M. Rizk "MultiDimensional Success Factors of Agile Software Development Projects", May 2015.

[24] Hadi Shirouyehzad et al. "The FMEA Approach to Identification of Critical Failure Factors in ERP Implementation.” July 2011.
[25] ICH-Q9 standard, INTERNATIONAL CONFERENCE ON HARMONISATION OF TECHNICAL REQUIREMENTS FOR REGISTRATION OF PHARMACEUTICALS FOR HUMAN USE “QUALITY RISK MANAGEMENT Q9” 09 Nov 2005.

[26] Mahmood Ali and Ying Xie "The quest for successful implementation: A new dynamic model for ERP Systems Implementation Innovation”,Aug 2012

[27] S. Vijayakumar Bharathi, R. Raman and Dhanya Pramod "A FPN Based Risk Assessment Model for ERP Implementation in Small and Medium Enterprises", 2014

[28] Nazli Sadat Safavi, Mahyar Amini, Azam Abdollahzadegan and Nor Hidayati Zakaria "An Effective Model for Evaluating Organizational Risk and Cost in ERP Implementation by SME”, Jun 2013

[29] Vijayakumar Bharathi, Dhanya Pramod and Ramakrishnan Raman "A FUZZY PETRI-NET BASED CONCEPTUAL MODEL FOR RISK PREDICTION IN ENTERPRISE RESOURCE PLANNING ACQUISITION DECISIONS FOR SMALL AND MEDIUM ENTERPRISES”, 18 Mar 2013

[30] Light. Zaglago, Idisemi. Apulu, Craig. Chapman and Hanifa Shah, Member "The Impact of Culture in Enterprise Resource Planning System Implementation", Jul 2013

[31] Ahmed O. R. Kholeif, Magdy Abdel-Kader and Michael Sherer "ERP Customization Failure: Institutionalized Accounting Practices,Power Relations and Market Forces", 2007

[32] Ahmed A. Elragal and Ayman M. Al-Serafi "The Effect of ERP System Implementation on Business Performance: An Exploratory Case-Study", 2011

[33] Salwa Alsamarai and Ziad. M.S Almashaqba "The Organizational Factors Affecting Enterprise Resource Planning Systems (ERPs) Implementation Success", 2009

[34] S. Bernardi et al. "Model-Driven Dependability Assessment of Software Systems", 2013

[35] pharmastate "https://pharmastate.blog/2017/11/12/riskmanagement-methods-and-tools/" Seen 31 DEC 2017.

[36] Rodrigo de Queiroz Souza, and Alberto José Álvares "FMEA AND FTA ANALYSIS FOR APPLICATION OF THE RELIABILITY-CENTERED MAINTENANCE METHODOLOGY: CASE STUDY ON HYDRAULIC TURBINES", 2008

[37] Clifton A. Ericson "Fault Tree Analysis - A History", 1999

[38] Ahmed Ali Baig, Risza Ruzli, and Azizul B. Buang "Reliability Analysis Using Fault Tree Analysis: A Review", June 2013

[39] Abdelaziz Berrado et al. "A Framework for Risk Management in Railway Sector: Application to RoadRail Level Crossings"2011

[40] Tim Sandle "The use of risk assessment tools for microbiological assessment of cleanroom environments", 2010

[41] Yonas Mitiku Degu, R. Srinivasa Moorthy 
"Implementation of Machinery Failure Mode and Effect Analysis in Amhara Pipe Factory P.L.C., Bahir Dar, Ethiopia”, 2014

[42] Hadi Shirouyehzad, Reza Dabestani and Mostafa Badakhshian "The FMEA Approach to Identification of Critical Failure Factors in ERP Implementation" , July 2011

[43] T. Frank et al. "Quality Risk Management Principles and Industry Case Studies”, 28 Dec 2008

[44] D. R. Prajapati "Implementation of Failure Mode and Effect Analysis: A Literature Review “, July 2012

[45] DAVID W. VINCENT, and BILL HONECK "Risk Management Analysis Techniques For Validation Programs" May 2004

[46] Agung Sutrisno and Tzong-Ru, "Service reliability assessment using failure mode and effect analysis (FMEA): survey and opportunity roadmap" 2011

[47] Rupy Sawhney et al. "A Modified FMEA Approach to Enhance Reliability of Lean Systems", 2010

[48] Mohamed-Habib MAZOUNI et al. "A PHA based on a systemic and generic ontology" 2007.

[49] Roland Mader et al. "Computer-Aided PHA, FTA and FMEA for Automotive Embedded Systems" 2011.

[50] S.I. Lao et al. "A real-time food safety management system for receiving operations in distribution centers" 2012.

[51] HE Xin, and TAO Xin "A Software Safety Test Approach Based on FTA and Bayesian Networks" 2011.

[52] Jong-Gyu Hwang, and Hyun-Jeong Jo

"Hazard Identificaiton of Railway Signaling System Usig PHA and HAZOP Methods " 2 FEB 2013.

[53] Silvianita et al. "Operational Risk Assessment Framework of Mobile Mooring System” 2011.
[54] Ioan Alfred Letia, and Adrian Groza "Developing Hazard Ontology for Supporting HACCP Systems in Food Supply Chains" 2010.

[55] Xi-Ping Zhu et al. "A Quantitative Comprehensive Safety Evaluation Method for Centrifugal Compressors Using FMEA-fuzzy Operations" 2013.

[56] Guoqi Li "A 14-Step Strategy of HACCP System Implementation in Snack Food Manufacturing" 30 AUG 2008.

[57] Guoqi Li "Ontology-based Reuse of Failure Modes for FMEA: Methodology and Tool” 2012.

[58] Yoshio Sakai et al. "An extended notation of FTA for risk assessment of software-intensive medical devices." 2013.

[59] XU Xin, et al. "Improvement \& Application of HAZOP Analysis for Batch Process with SDG" 2010.

[60] Youngjung Geum et al. "A systematic approach for diagnosing service failure: Service-specific FMEA and grey relational analysis approach” 29 JUL 2011.

[61] wikipedia "https://en.wikipedia.org/wiki/Failure_mode_and_effects analysis" Seen 30 DEC 2017.

[62] Pharmamirror "http://www.pharmamirror.com/knowledgebase/pharmaceutical-dictionary/failure-mode-effectsanalysis-fmea/" Seen 31 DEC 2017.

[63] ASQ "http://asq.org/learn-about-quality/processanalysis-tools/overview/fmea.html" Seen 31 DEC 2017.

[64] Coursehero "https://www.coursehero.com/file/p4064b4/ValidatonPractces-conTd-Risk-ManagemenT-ools-Basic-riskmanagement-facilitaTon/" Seen 31 DEC 2017.

[65] barringer1 "http://www.barringer1.com/nov04prb.htm" $\begin{array}{llll}\text { Seen } & 31 & \text { DEC }\end{array}$ 